\title{
Street View
}

Liebe Leserinnen, liebe Leser,

der Vorgänger Ludwig Erhards als Direktor der Verwaltung für Wirtschaft in der Bizonenverwaltung war Johannes Semler. Seinerzeit, 1947, spendeten die Amerikaner der hungernden deutschen Bevölkerung Mais. Mais war aber hierzulande nur als Futtergetreide geläufig. Semler äußerte sich dazu: „Die Besatzer essen unseren guten Weizen und liefern uns dafür Hühnerfutter." Die Besatzer beendeten seine Karriere abrupt. ${ }^{1}$ Mais - das sollte Semler gewusst haben - ist ein amerikanisches Nationalsymbol. Jeder Amerikaner hat bereits in der Vorschule gelernt, dass die auf der Mayflower-Reise ausgehungerten Pilgrim Fathers auf Cape Cod an Land gingen und von Indianern u.a. mit Mais bewirtet wurden. Doch den hungernden Deutschen hatte Semler aus der Seele gesprochen und sie bedauerten, dass mit ihm ein tüchtiger Mann hatte gehen müssen.

Die Amerikaner von 1947 zeigten kein Verständnis für das Argument, dass die Deutschen in ihren Gefühlen, Vorlieben und Gewohnheiten anders geartet sind als Amerikaner. "Baloney - People are the same all over the world", alle Menschen sind sich gleich. Was den Amerikanern bekommt, das bekommt auch den Deutschen. Auftretende Unterschiede sind durch den unterschiedlichen zivilisatorischen Entwicklungsstand bedingt und werden sich ausgleichen - ein Besatzer-Basta. Wer hätte aber damals gedacht, dass das Basta auch Recht behalten würde? Was nicht alles haben die Deutschen seit 1947 von den Amerikanern übernommen. Mit 1947er Augen besehen, sind die heutigen Unterschiede im Way of Life der beiden Völker kaum feststellbar.

Aber Unterschiede sind trotzdem noch da. Kürzlich im Fernsehen: Der Bundesminister des Inneren sagte: Die Aufregung über den Internet-Dienst Google Street View ist typisch für die Deutschen. Sie sind dagegen, dass ihr Haus im Internet gezeigt wird; das verletze die Intimsphäre. Doch sehen sie sich die Aufnahmen auf dem Bildschirm mit Interesse an, wenn sie etwa ein Haus erwerben wollen. Ferner sagte der Minister: Die Amerikaner haben damit kein Problem. So ist es. Und warum die Deutschen? Warum lehnen sie Street View ab? Zunächst zum Vergleich Google Earth, eine ähnliche Dienstleistung. Sie ist in Deutschland sehr beliebt. Mit ihr kann man aus der Satellitenperspektive alles Mögliche auf der Erdoberfläche betrachten, neben Jerusalem und der Kalahari auch das eigene Haus. Man staunt über die Details der Wiedergabe und ist entzückt. Das ist einem in den Orbit entrückten Satelliten zu verdanken. Er wird hoch geschätzt. Wenn aber Kamera-Autos für Street View durch die Straßen fahren, fühlen sich viele Deutsche bedroht und rufen nach dem Gesetzgeber. Dem Satelliten sehen sie die Neugierde nach, nicht aber den Kamera-Autos. Der Satellit im Orbit ist innen vertrauenswürdiger als das Auto auf der Straße, obwohl er ein Außerirdischer ist und noch dazu militärischer Herkunft.

Man kann diese Diskrepanz mit den unterschiedlichen Umständen zu erklären suchen, stößt aber immer auf Einwände. Das liegt letztlich daran, dass die artikulierten Meinungen auf unartikulierbaren Gefühlen beruhen. Dem einen ist es ungemütlich, der andere ärgert sich über das smarte Google, hält sich für ausgenützt, wieder einer hasst Technik als solche etc. Auf Gefühlen aber beruht unsere Werteordnung. Die kommunizierten Gefühle verdichten sich zur allgemeinen Überzeugung, dass etwas Bedrohliches entsteht.

In Deutschland, liebe Leserinnen und Leser. Und nicht in Amerika? Der gleiche Internetdienst! Der wirkt allein schon aus ökonomischen Gründen auf den Ausgleich der Unterschiede hin. Werden sich also die Amerikaner auch bedroht fühlen, oder werden sich die Deutschen zu amerikanischer Unbekümmertheit hin - wie gehabt - entwickeln?

Mit freundlichen Grüßen, Ihr

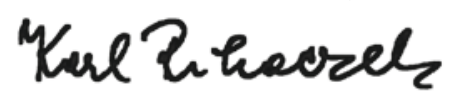

1 Ludwig Erhard hat sie erfolgreich zu einem guten Ende gebracht.. 